\title{
DIGITAL LITERACY ASSESSMENT OF UNDERGRADUATE STUDENTS FROM PHYSICAL EDUCATION PROGRAM OF THAILAND NATIONAL SPORTS UNIVERSITY
}

\author{
Narumon Rodniam \\ Faculty of Education, Thailand National Sports University, Chumphon Campus, Thailand
}

\begin{abstract}
The purposes of this research were to 1) assess levels of digital literacy of undergraduate students from Physical Education Program of Thailand National Sports University (TNSU); and 2) compare digital literacy levels of the students with consideration on the variables of sex and class level. Using a quantitative research method, the sample of this study consisted of 400 undergraduate students from Physical Education Program, Faculty of Education, TNSU, who were studying in their first semester of the academic year 2019. It was obtained via a multistage random sampling technique. The data collection tool was the Digital Literacy Assessment for Undergraduate Students of Wawta Techataweewan and Ujsara Prasertsin (2016), which contains four components for a total of 54 questions. The data analysis was relied on descriptive statistics and multiple techniques, including independent-samples t-test, one-way ANOVA, and post-hoc comparison with Scheffe's method. The results revealed that: 1) the undergraduate students from the Physical Education Program of TNSU had a high level of overall digital literacy, 2) the female students had significantly higher digital literacy than males, and 3 ) the students in the $5^{\text {th }}$ class level had higher digital literacy than those in the first-class level significantly at the significance level of .05. However, no significant differences among other class levels were discovered.
\end{abstract}

\section{KEYWORDS}

Digital Literacy, Undergraduates, Thailand National Sports University

\section{INTRODUCTION}

At present, the Internet and digital technology have become an infrastructure for daily living of many people. Therefore, it is necessary for people in society to have skills and knowledge in digital technology in order to gain access to contents, communications, and data processing in various forms via critical and moral thinking to enhance the capacity of individuals in using media and digital technology for utmost benefits. As a result, digital literacy has been specified as an essential learning skill of citizens in the $21^{\text {st }}$ century.

Newman. (2012) has defined that digital literacy refers to abilities in terms of awareness and technical skills in using information and communication technologies for retrieving, assessing, creating, and communicating information as intended. Similarly, Cornell University (2009) defines digital literacy as an ability to retrieve, assess, utilize, share, and create content based on information technology and the Internet. In their case, students of Cornell University had to be able to write a report, create and make presentation with multimedia, and post information related to oneself or others on the Internet. All of these requirements involve common activities that the students practice daily. Bawden (2008) defined that digital literacy refers to literacy in computer and Information and Communication Technology (ICT) that enables the person to read, understand, create, communicate, assess, and recreate knowledge from digital information based on good attitudes toward learning and using digital media morally and responsibly. It can therefore be seen that digital literacy does not involve only with ICT skills, but also other aspects of skills namely: 1) cognitive skills, which require knowledge and understanding; 2) motor skills, which are important when doing operations related directly and indirectly to technologies; 3) social skills, which guide good practices such as being a good citizen of the society who always regard impact on the community and overall people; and 
4) emotion skills, which enable the person to manage one's own emotion and be aware of effects on interpersonal relationship. (Stepić, Gordana, 2013).

The fast-growing number of digital learning media leads to an enormous learning source being closest to the learners. (Simpson\&Obdalova, Olga, 2014). Consequently, digital technology has played a more significant role in education. Students in education programs and young-generation teachers should acquire skills and capacities in digital literacy to promote learners to learn better within the digital environment and to manage digital classrooms more smoothly and efficiently. (Krumsvik, 2008, Maderick, Zhang, Hartley, \& Marchand, 2015).

From investigating literature related to the digital literacy of Thai students within the past five years, researches on this topic are quite limited. In the case of Thailand National Sports University (TNSU), no research has been found so far to conduct on assessing the digital literacy of students. However, as research from Asri Saidi, Sittisak Boonhan, and Jitratda Thamathes (2019) found that keeping media, information, and digital literacy is one of the competencies of physical education teachers in the $21^{\text {st }}$ century. For this reason, to prepare physical education teachers in the $21^{\text {st }}$ century, the researcher finds that it is essential to study and assess the digital literacy levels as a whole and also for each component of the digital literacy of Physical Education students inTNSU. The digital literacy levels should also be assessed to compare between students of different sexes, and class levels, which had hypotheses were students of different sexes (No.1), and class levels (No.2) have different levels of digital literacy - this study to reveal strengths and weaknesses in the digital literacy skills of the students. The findings are expected to provide useful information for planning, supporting, promoting, and developing learners in response to the ongoing progress of digital technology.

\section{METHODOLOGY}

A quantitative research method was employed for this study. The sample consisted of 400 undergraduate students of Physical Education Program of TNSU who were studying in their first semester of academic year 2019. Applying a multi-stage sampling technique, the sample was acquired through 2 stages.

Stage 1: the randomization was made according to regions (Northern, North-eastern, Central, and Southern regions) so that two campuses were selected for each region. The derived 8 campuses consisted of Sukhothai Campus, Lampang Campus, Bangkok Campus, Samutsakhon Campus, Udonthani Campus, Mahasarakham Campus, Chumphon Campus, and Krabi Campus.

Stage 2: stratified random sampling was applied to obtain samples throughout all 5 class levels. This stage yielded 93 students from class level 1,89 students from class level 2, 76 students from class level 3, 71 students from class level 4 , and 70 students from class level 5 . After that, the proportion of students from each of the eight campuses as determined in Stage 1 was specified.

The tool used for assessing the digital literacy of Thai undergraduate students in this study is the assessment developed by Wawta Techataweewan and Ujsara Prasertsi. (2016). (This 5-level rating scale assessment contains 54 questions that cover 4 components of digital literacy, namely operation skills, thinking skills, collaboration skills, and awareness skills. It is showed at https://forms.gle/YjybFRnhJnCPy38E7) The reliability value of the whole questionnaire was determined using Cronbach's Alpha coefficient, and was found to be equal to 0.91 .

The data were collected by allowing the sample to complete the questionnaire either in the campus's computer laboratory or via their smartphones during July $22^{\text {nd }}$ to August $22^{\text {nd }}, 2019$. After finishing the data collection process, the research checked for accuracy and completeness of answers in all questionnaires. Data analyses were then conducted by initially finding descriptive statistics, namely means and standard deviations. Next, the difference in the mean values of the digital literacy of students with different sexes was tested by means of Independent-samples t-test at the significance level of .05. Digital literacy levels of students in different class levels were then analyzed using an F-test in One-Way ANOVA, followed by post-hoc comparison with Scheffe's method. Subsequently, the results were interpreted by relying on the mean-value criteria according to the concept of Best (Best. 1970) as follows: $4.50-5.00=$ highest, $3.50-4.49=$ high, $2.50-3.49=$ moderate, $1.50-2.49=$ low, and $1.00-1.49=$ lowest levels. 


\section{RESULTS}

This research received answers from a total of 400 students who are mostly males $(68.25 \%)$. Categorized by class levels, most of the responders were first-year students $(23.30 \%)$, followed by second-year students $(22.50 \%)$, and third-year students $(19.00 \%)$. The research results were obtained as follows.

\subsection{Results of the Analysis on Digital Literacy Level of the Undergraduate Students}

The undergraduate students from Physical Education Program of TNSU had overall digital literacy at a high level. Considering at each component, there was only one aspect that their digital literacy was at a moderate level, which is the operation skills aspect. The remaining aspects were at a high level. Ranked by their mean values, these aspects are awareness skills, collaboration skills, and thinking skills, respectively. Detailed results for each component can be described below.

1) For the awareness skills, all indicators were found to be at a high level, with 'Self-defense' having the highest mean, followed by 'Morality.' 'Law awareness' was the indicator that received the lowest mean value.

2) For the collaboration skills, two indicators were found to be at a high level. 'Teamwork' was the indicator with the highest mean, followed by 'Networking.' The indicator 'Sharing' was at a moderate level.

3) For the thinking skills, all indicators were at a high level. 'Creative thinking' had the highest mean, followed by 'Assessment ability,' while 'Analysis ability' had the lowest mean.

4) For the operation skills, only one indicator, i.e., 'Cognitive domain,' was at a high level. All other indicators were at a moderate level. Ranked by mean values, they are 'Presentation' and 'Invention,' respectively. As shown in Table 1.

\subsection{The Results from Comparing Digital Literacy Levels of the Undergraduate Students by Considering Sex and Class Level as Variables}

1) For the variable of sex, it was found that the undergraduate students from Physical Education Program of TNSU with different sexes had significantly different levels of digital literacy. This finding corresponds with the Research Hypothesis No. 1, as female students had significantly higher digital literacy than males. Considering at each component, the comparison tests revealed that the undergraduate students from Physical Education Program of TNSU with different sexes had different levels of digital literacy in two components namely the collaboration skills and the awareness skills, with the female students having higher digital literacy levels than the males at the significance level of .05. However, for the operation skills and the thinking skills, both sexes did not have significant difference in their literacy. As shown in Table 2

2) For the variable of class level, it was found that the undergraduate students from Physical Education Program of TNSU who studied in different class levels had different levels of digital literacy, which is in according with the Research Hypothesis No.2. Based on the post-hoc comparison between each pair, the fifth-year students had higher digital literacy than the first-year students, at the significance level of 0.5 , while other pairs expressed no significant differences. Considering at each component, the analysis results revealed that the undergraduate students from Physical Education Program of TNSU of different class levels had different digital literacy levels in two components namely the operation skills and the thinking skills. For the operation skills, the fourth-year students had higher skills than the first-year students, at the significance level of . 05 . In case of the thinking skills, the fifth-year students had higher thinking skills than the firstyear students, at the significance level of .01. However, for the collaboration skills and the awareness skills, students of all class levels showed no differences in their literacy.

\section{DISSCUSSION}

1. The undergraduate students from Physical Education Program of TNSU had overall digital literacy in a high level. This is likely to be because the sampled students were born during the years 1996-2000, which makes them be considered as the new generation or Gen $\mathrm{Z}$ citizens. Being born in the digital era, they are 
naturally accustomed and have expertise in using digital technology. (Greedisgoods, 2018; Sarunjade, 2016) That explains why their overall digital literacy is at a high level. Simultaneously, digital technology has been utilized widely, with communication infrastructure being expanded to cover the whole country. The subsequent higher stability and cheaper price of high-speed broadband communication promotes higher use of the internet. (Ministry of Information and Communication Technology, 2015). In addition, the policy to develop quality and standard of education as specified in the National Education Act, B.E. 2542, and its revision B.E. 2545 requires that all universities must manage education according to the Thai Qualifications Framework for Higher Education, The standard No. 5 concerning the digital analysis, communication, and IT skills (Wicharn Panich, 2009), specifies that there must be utilization of information technology and integrated communication skills in education. Moreover, TNSU has supported education in a form of integrated learning by establishing online education and using multimedia in the teaching with integration of digital technology into various courses. The research result is in agreement with the result of Wawta Techataweewan and Ujsara Prasertsin (2016) whose study revealed that the undergraduate students in Bangkok and vicinity had a high level of digital literacy. Similarly, Ng. (2012) and Shopova. (2014) also found that the sampled students had a high level ofdigital literacy. However, the result is incompatible with those of Bullen; Morgan;\& Qayyum. (2011), Dornaleteche-Ruiz; Buitrago-Alonso; \& Moreno-Cardenal. (2015) and Ting. (2015) whose studies were conducted with students in multiple countries and found the levels of digital literacy to range from a moderate level to a basic level. This contrary might be due to differences in the applied assessments and the technological environments of each country.

2. The undergraduate students from Physical Education Program of TNSU had the highest mean value of digital literacy in the awareness skills aspect. This is possibly because the government pays attention to and supports digital technology, leading to origination of campaigns to distribute information and examples of wrong doings against the Computer-related Crime Act B.E. 2550 widely via popular social media such as Facebook, Line, Twitter, etc. In addition, the studied group of students belongs to the Physical Education Program, which is a program for professional teacher education and its curriculum demands learning in information technology and morality in using information technology. Therefore, the students are aware of appropriate practices regarding information technology and digital technology. This result also corresponds with the study of Skonwan Paruang (2011) who found that the students of professional teacher education had the highest capacity in the Affective domain. A research of Ozdamar-eskin; Ozata; \& Banar (2015) also revealed that the students had the highest levels of digital literacy in 'Safety' and 'Morality', as compared to other aspects.

3. This study found that the undergraduate students from Physical Education Program of TNSU had a moderate level of digital literacy in the aspect of operation skills. This is probably because most of the students used digital technology in a role of end users rather than as an inventor or a presenter. It can be seen from the mean score for each indicator in the operation skills component that the students had a high mean score for the 'Cognitive domain' indicator, but their scores for the 'Invention' and 'Presentation' indicators were at a moderate level. Inventing something from digital technology requires higher knowledge and skills than regular usage of the technology. Presentation also requires application of techniques and designs to attract attention from the audience. Hence, presenters have to know how to use online media properly for their presentation, especially when using multimedia for stimulating interest and enhancing understanding of audience more than using merely text. This research finding is in agreement with the study of Wawta Techataweewan and Ujsara Prasertsin (2016), which found that the undergraduate students in Bangkok and vicinity had a moderate level of digital literacy in terms of operation skills. The research of Ting (2015) also revealed that most students used multimedia technology only at a basic level, and they lacked technical knowledge of advanced multimedia usage. However, this finding disagrees with the studies of $\mathrm{Ng}$. (2012) and Shopova. (2014), which showed that most students had a high level of digital literacy in the technical aspect or ICT aspect. The disagreement could be due to differences in the study areas and the technological environments.

4. The undergraduate students from Physical Education Program of TNSU with different sexes had different levels of digital literacy. Female students were found to have higher digital literacy than males. This finding could be attributed to difference learning between males and females. Likewise, the research of Dornaleteche-Ruiz; Buitrago Alonso; \&Moreno-Cardenal. (2015) conducted with Spanish population found that people of different sexes had different levels of digital literacy. The research of Li; \& Ranieri. (2010) also revealed that the female Chinese teenagers had higher capacity in digital technology than the male 
counterpart. On a contrary, the research of Hall; Nix; \& Baker. (2013), conducted with United Kingdom students, found that the male students paid more attention to digital literacy than the females.

5. The undergraduate students from Physical Education Program of TNSU who studied in different class levels were found to have different levels of digital literacy, with the fifth-year students had higher digital literacy than the first-year students, although there was no significant differences between other class levels. This should be because the fifth-year students have learned almost all course contents in the curriculum and are about to perform teaching in an academy outside the university. This makes them have greater maturity and experience for overall digital literacy than the first-year students who have just entered the university and never learned required courses for teacher production. This finding corresponds to those of Li \&Ranieri. (2010) who found individuals of different ages to have different levels of digital literacy. However, they found the younger teenagers to have higher digital capacity than the older ones. This is possibly because of difference in the studied populations and the assessments. The digital literacy assessment tool in this study has been designed not only for assessing operation skills but also for awareness skills, thinking skills, and collaboration skills

\section{CONCLUSION}

As this research found that the undergraduate students from Physical Education Program of TNSU had just a moderate level of digital literacy in the operation skills, strategies should be implemented to improve digital literacy of students in terms of operation skills. The learning management should allow students to play a role of an innovative inventor and/or a presenter based on application of various forms of digital technology. The learning environment should be managed to facilitate digital media usage of all students together. Besides that, the team responsible for developing students in Physical Education Program of TNSU should assess digital literacy skills of first-year students in order to know weaknesses and strengths that are useful for planning to develop them. Teachers and technical supporting personnel of the Faculty or persons responsible for developing students in Physical Education Program of TNSU should receive training to acquire knowledge on digital literacy so that they can understand and apply the knowledge to their teaching and their technical supports. For recommendations for future research, we hope study in factors or requirements for promoting digital literacy to students of Physical Education Program or other programs with similar learning environments should be studied further in order to obtain guidelines for developing appropriate digital literacy to that specific group of students.

\section{ACKNOWLEDGEMENT}

I would like to express my gratitude to an anonymous reviewer for their helpful comments. In addition, this research would not be conducted successfully without moral supports from my family and friends. Finally, I would like to send many sincere thanks to the Thailand National Sports University, Chumphon Campus for the research support towards this opportunity.

\section{REFERENCES}

Asri Saidi, Sittisak Boonhan, and Jitratda Thamathes, 2019. Competency of PE Teachers in the $21^{\text {st }}$ Century $e$-Journal of Education Studies, Burapha University. (In Thai), Vol.1 No.4, pp. 14-24.

Bawden, D. Origins and Concepts of Digital Literacy, 2008. In Digital Literacies: Concepts, Policies and Practices. Ed. C. Lankshear \& M. Knobe. Peter Lang, New York, pp. 17-32.

Bullen, Mark; Morgan, Tannis; \& Qayyum, Adnan, 2011. Digital Learners in Higher Education: Generation is Not the Issue. Journal of Learning and Technology. Vol. 37, No.1, pp. 1-24.

Cornell University. 2009. What is Digital Literacy?. [Online]. Available: http://digitalliteracy.cornell.edu/

Dornaleteche-Ruiz, Jon; Buitrago-Alonso, Alejandro; \& Moreno-Cardenal, Luisa, 2015. Categorization, Item Selection and Implementation of an Online Digital Literacy Test as Media Literacy Indicator. Comunicar. (In Spanish). Vol. 22, No.44, pp.177-185. 
Greedisgoods, 2018. Who is Gen-Z. (In Thai).[Online]. Available: https://greedisgoods.com/

Hall, Marion; Nix, Ingrid; \& Baker, Kirsty, 2013. Student Experiences and Perceptions of Digital Literacy Skills Development: Engaging Learners by Design?. The Electronic Journal of e-Learning. Vol. 11, No.3, pp.168-272.

Krumsvik, R. J., 2008. Situated learning and teachers' digital competence. Education and Information Technologies. Vol. 13, No. 4, pp. 279-290.

Li, Y., \& Ranieri, M, 2010. Are 'digital natives' really digitally competent? A study on Chinese teenagers. British Journal of Educational Technology. Vol. 41, No.6, pp.1029-1042.

Maderick, Zhang, Hartley, \& Marchand, 2015. Preservice Teachers and Self-Assessing Digital Competence. Journal of Educational Computing Research. Vol. 54, No. 3, pp. 4-38.

Ministry of Information and Communication Technology, 2015. Report of the internet user behavior survey in Thailand. Bangkok.

Newman B.L, 2012. Defining Digital Literacy.Available:http://www.districtdispatch.org/2012/04/defining-digitalliteracy.

Ng, Wan, 2012. Can We Teach Digital Natives Digital Literacy?. Computers \& Education. Vol.59, pp. 65-1078.

Ozdamar-Keskin, Nilgun; Ozata, Fatma Zeynep; \& Banar, Kerim, 2015. Examining Digital Literacy Competences and Learning Habits of Open and Distance Learners. Contemporary Educational Technology. Vol.6, No.1, pp.74-90.

Sarunjade, 2016. 3 behaviors of "Generation Z" (In Thai) [Online]. Available: https://www.marketingoops.com/news/tech-update/3-behaviors

Simpson\&Obdalova, Olga, 2014. New Techno-logies in Higher Education-ICT Skills of Digital Literacy? Procedia-Social and Behavioral Sciences. Vol.154, pp.104-111.

Skonwan Paruang, 2011. Development of competency in information and communication technology of students in education education. Thesis in Political Science Bangkok: Chulalongkorn University. (In Thai)

Shopova, Tatiana, 2014. Digital Literacy of Students and Its Improvement at the University. Journal on Efficiency and Responsibility in Education and Science. Vol. 7, No.2, pp. 26-35. Doi: 10.7160/eriesj.2014.070201.

Stepić, Gordana, 2013. Possibilities for the Development of Digital Literacy of the Junior Grades Students of Primary School. Proceedings of eLearning and Software for Education, pp.368-375.

Ting, Yu-Liang, 2015. Tapping into Students' Digital Literacy and Designing Negotiated Learning to Promote Learner Autonomy. Internet and Higher Education. Vol. 26, pp.25-32.

Wawta Techataweewan, \& ujsara Prasertsin, 2016. Development of digital literacy test for undergraduate students. (In Thai). Department of Library and Information Science Faculty of Humanities Srinakharinwirot University.

Wawta Techataweewan, \& Ujsara Prasertsin, 2016. Digital Literacy Skills For Developing Learning Ability of Undergraduate Students: A Qualitative Interview Approach. Proceedings of 53 ${ }^{\text {rd }}$ ISERD International Conference. Zurich, Switzerland, 30 ${ }^{\text {th }}-31^{\text {st }}$ October 2016.

Wicharn Panich, 2009. TQF [Online]. Available: http://www.academic.nu.ac.th/

\section{APPENDIX}

Table 1. Digital literacy levels of the undergraduate students from Physical Education Program of TNSU

\begin{tabular}{lccccl}
\hline Components of DL & $\bar{X}$ & SD & sk & kt & Interpret \\
\hline Overview DL level & $\mathbf{3 . 6 2 1}$ & $\mathbf{0 . 6 2 2}$ & $\mathbf{- 0 . 5 0 8}$ & $\mathbf{0 . 2 7 3}$ & High \\
\hline 1.Operation skills & $\mathbf{3 . 3 1 2}$ & $\mathbf{0 . 7 3 2}$ & $\mathbf{- 0 . 2 2 5}$ & $\mathbf{- 0 . 2 8 5}$ & moderate \\
\hline Cognitive domain & 3.586 & 0.686 & -0.424 & 0.288 & High \\
\hline Invention & 2.955 & 0.946 & -0.154 & -0.632 & moderate \\
\hline Presentation & 3.396 & 0.835 & -0.270 & -0.414 & moderate \\
\hline 2.Thinking skills & $\mathbf{3 . 6 7 7}$ & $\mathbf{0 . 6 9 5}$ & $\mathbf{- 0 . 5 0 6}$ & $\mathbf{0 . 3 2 8}$ & High \\
\hline Analysis ability & 3.553 & 0.822 & -0.351 & -0.010 & High \\
\hline Assessment ability & 3.731 & 0.776 & -0.453 & 0.249 & High \\
\hline Creative thinking & 3.748 & 0.766 & -0.492 & 0.061 & High \\
\hline 3.Collaboration skills & $\mathbf{3 . 5 7 5}$ & $\mathbf{0 . 7 2 9}$ & $\mathbf{- 0 . 4 3 2}$ & $\mathbf{0 . 1 0 9}$ & High \\
\hline Teamwork & 3.688 & 0.747 & -0.517 & 0.298 & High \\
\hline Networking & 3.658 & 0.879 & -0.491 & -0.035 & High \\
\hline Sharing & 3.378 & 0.873 & -0.335 & -0.284 & moderate \\
\hline
\end{tabular}




\begin{tabular}{lccccc}
\hline Components of DL & $\bar{X}$ & SD & sk & kt & Interpret \\
\hline Overview & 3.575 & 0.729 & -0.432 & 0.109 & High \\
\hline 4.Awareness skills & $\mathbf{3 . 9 1 9}$ & $\mathbf{0 . 7 8 8}$ & $\mathbf{- 0 . 7 7 8}$ & $\mathbf{0 . 1 4 1}$ & High \\
\hline Morality & 3.903 & 0.818 & -0.730 & 0.141 & High \\
\hline Law awareness & 3.895 & 0.927 & -1.021 & 0.669 & High \\
\hline Self-defense & 3.960 & 0.854 & -0.743 & 0.273 & High \\
\hline
\end{tabular}

Table 2. Comparison on digital literacy levels of the undergraduate students from Physical Education Program of TNSU based on the variable of sex, as a whole and separated for each component

\begin{tabular}{lcccccc}
\hline \multicolumn{1}{c}{ DL } & Sex & $\mathbf{n}$ & $\overline{\mathbf{X}}$ & SD & $\mathbf{d f}$ & $\mathbf{t}$ \\
\hline \multirow{2}{*}{ Overview of DL level } & Male & 273 & 3.578 & 0.627 & 398 & $-2.020^{*}$ \\
\cline { 2 - 7 } Female & 127 & 3.713 & 0.604 & & \\
\hline \multirow{2}{*}{.Operation skills } & Male & 273 & 3.289 & 0.734 & 398 & -0.932 \\
\cline { 2 - 7 } 2.Thinking skills & Female & 127 & 3.362 & 0.728 & & \\
\hline \multirow{2}{*}{ 3.Collaboration skills } & Male & 273 & 3.652 & 0.696 & 398 & -1.064 \\
\hline \multirow{2}{*}{ 4. Awareness skills } & Male & 273 & 3.518 & 0.727 & 398 & $-2.314^{*}$ \\
\cline { 2 - 7 } & Female & 127 & 3.698 & 0.722 & & \\
\cline { 2 - 7 } & Male & 273 & 3.854 & 0.787 & 398 & $-2.435^{*}$ \\
\hline
\end{tabular}

${ }^{*} p<.05$ 